\title{
Educar: transbordar a ética ambiental
}

\section{Professora Assistente da Universidade do Estado do Rio de Janeiro \\ Doutoranda em Educação pela UNICAMP \\ Lincoln Tavares Silva \\ Professor Assistente da Universidade do Estado do Rio de Janeiro \\ Doutorando em Educação pela USP}

\section{Resumo}

Refletimos sobre educação, ética e suas relações com consumo, ambiente e vida. Discutimos criticamente a sociedade globalizada cujas relações socioambientais se baseiam no individualismo e na competitividade. Assim refletem concepções globalitárias de organização social, econômica e cultural sobre as diferentes comunidades. Ideias como consumo verde, crise ambiental, modelo cívico, qualidade de vida, responsabilidade socioambiental e senso comum emancipatório serão incorporadas. Retratamos estratégias dominantes e alienantes utilizadas e as possíveis "brechas" e "transbordamentos" que permitirão debates e reflexões no campo educacional para possíveis ações de defesa da cidadania e da vida.

Palavras-chave: Ética; Educação; Ambiente.

\begin{abstract}
We reflected on education, ethics, and its relations with consumption, environment and life. We critically discuss the globalised society whose socioenvironmental relations are based on individualism and competitiveness. Thus reflect globalitarian conceptions of social, economic and cultural organization over the different communities. Ideas such as green consumption, environmental crisis, civic model, quality of life, environmental responsibility and emancipative common sense will be incorporated. We showed dominant and alienating strategies used and the possible "paths" and "overflows" which will allow discussions in the educational field for possible actions in defense of life and citizenship.
\end{abstract}

Key-words: Ethics; Education; Environment. 
As gerações anteriores legaram para as nossas uma difícil missão: a refundição das cidades que elas ergueram na ignorância ou na incúria de todos os princípios da salubridade pública. Ruas mal traçadas, construções tortuosas, estabelecimentos mal ajeitados, casebres úmidos e sombrios invadindo a via pública, pavimentação incompleta, sistemas defeituosos de distribuição e de escoamento das águas: tais são os defeitos das antigas cidades (Michel Lévy, 1869).

$\mathrm{N}$

ão seria estranho que pensássemos o texto acima como pertencente a um estudioso das cidades contemporâneas, notadamente de algumas de nossas cidades brasileiras ou latino-americanas. Quem não consegue imaginar o ambiente descrito e as condições de vida nele instaladas em imagens que vemos cotidianamente em nossas andanças pela cidade ou nos noticiários da mídia? Estranho é que as condições degradantes de vida e do meio ambiente existentes nas sociedades industriais em constituição na época do Doutor Lévy, ainda se façam marcantes depois de 140 anos.

Neste ensaio, nos propomos a discutir em que bases o cenário predominante na sociedade moderna se constituiu, assim como pretendemos tecer algumas das críticas que podem e devem ser pensadas, a partir do espaço escolar e de outros espaços de partilha de vida (Brandão, 2005), no intento de buscar caminhos compartilhados de sobrevivência digna e sustentável de nossa civilização.

Ao tratarmos dos problemas ambientais hoje, embora muitas vezes nos prendamos as catástrofes naturais que existem desde que o mundo se formou, estaremos de fato nos preocupando com aqueles que interferem nos desequilíbrios dos sistemas naturais produzidos pelo homem. Neste caso, compreendemos que os impactos desta ação podem inclusive acelerar os processos naturais, ampliando ou precipitando as catástrofes naturais, dando-lhes efetiva característica de flagelos sociais.

Como seres auto-reflexivos e únicos nesse sentido, também podemos entender que somos responsáveis por ações e consequências para nós e para os outros seres. Tais ações têm, necessariamente, implicações morais e não 
podem ser analisadas somente pelos aspectos descritivos. A degradação ambiental é consequência de decisões e de ações humanas, tecidas na sociedade, em diferentes culturas. Portanto, a análise deste painel não pode centrar-se apenas nos termos descritivos, devendo levar em conta, também, os aspectos normativos de sua efetivação.

As ideias subjetivas ou juízos morais que as pessoas possuem sobre o que deve (ou não) ser feito, o que é certo ou errado, são fundamentais nas análises de questões ambientais.

Dito isto, compreendemos que os próprios seres humanos tornaram-se objeto de análise, não apenas como vítimas de perigos ou riscos ambientais, mas como produtores das causas da poluição e da degradação dos ambientes. Tais questões ambientais adquirem, de fato, um componente socioambiental, pois não se referem apenas ao objeto legítimo da ciência natural, mas também das ciências humanas e sociais, incluindo a educação e a filosofia.

Portanto, entendemos que qualquer apreciação que se faça sobre as relações da sociedade com o ambiente deve possuir sob aspecto formativo, que alie teoria e prática, componentes necessariamente fundamentados na educação e na ética que ponham em discussão os modelos que nos conduziram a tal escala e estado de injustiça, degradação e risco.

Ao tratarmos do juízo moral, na verdade nos referimos aos “juízos éticos”, ou seja, as razões ou justificativas para costumes ou ações. O termo ética tem suas origens no grego ethos, que basicamente tinha o mesmo significado do termo moralidade, cuja origem vem do termo latino mores (costumes ou tradições) ${ }^{1}$. Frequentemente a filosofia trata o termo moral ou moralidade como base para costumes e tradições que de fato existem na sociedade ou num grupo cultural. Nesse texto, nos baseamos em Eckensberger (2001) e partimos da premissa de que a ética e os "juízos éticos” não se referem ao mundo como ele é, mas como ele deveria ser.

\footnotetext{
${ }^{1}$ Para maior aprofundamento ver: BOFF, Leonardo. Ethos mundial: um consenso mínimo. Rio de Janeiro: Sextante, 2003, 131p.
} 
Desse modo, embora nos preocupemos em como os sujeitos agem ou agiriam numa situação particular, focamos principalmente nossa abordagem no modo como os mesmos devem agir.

Acreditamos que o caminho escolhido não impede que nos embasemos na crítica ao cenário socioambiental contemporâneo. Mais ainda, acrescentamos que o tratamento das questões éticas necessárias à transformação desse cenário deve considerar, como já afirmara Lutz Eckensberger, que o desenvolvimento dos juízos éticos ou morais acontece num incremento sistemático de complexidade e abrangência de elementos de ações conflitantes, imaginárias ou realmente percebidas pelos sujeitos em diferentes grupos e sociedades. E como encontramos o cenário socioambiental hodierno?

Conforme já enfocamos, proporemos uma discussão pautada na crítica ao modelo de sociedade globalizada, no qual as relações socioambientais têm se fundamentado na perspectiva dos interesses individuais e da competitividade. Ensaiamos proporcionar, sem esgotar, uma discussão pautada em aspectos da contemporaneidade que envolvam a conformação na qual os diferentes sujeitos sociais encontram-se presentes, de acordo com seus comprometimentos, contradições sociais, visões de mundo e perspectivas de consumo. Ideias como cidadania, consumo verde, crise ambiental, modelo cívico, senso comum emancipatório, e outras, advindas de diversos pensadores, serão incorporadas.

Ressaltamos que a abordagem concretizada na discussão das influências e determinações econômicas e culturais impostas verticalmente pela racionalidade hegemônica reforçadas, em tempos de globalização, pelas relações estabelecidas entre sujeitos transformados em consumidores e o meio ambiente, admite constituir um retrato das estratégias dominantes e alienantes utilizadas, assim como, das possíveis “brechas” que permitirão ações de defesa da cidadania e da vida nos diferentes lugares do planeta.

Na caracterização do sujeito contemporâneo, partimos de uma constatação inicial básica, em concordância com Milton Santos (1993), 
acerca do consumidor e do cidadão, inclusive do chamado consumidor verde, a saber:

em lugar do cidadão surge o consumidor insatisfeito e, por isso, voltado a permanecer consumidor. Sua dependência em relação aos novos objetos limita sua vocação para obter uma individualidade e reduz a possibilidade dos encontros interpessoais diretos e enriquecedores, porque simbólicos em sua própria origem (SANTOS, 1993, p. 17).

Nessa perspectiva, o consumidor-usuário é aquele indivíduo a ser persuadido, objetivando que os padrões de produção e consumo se mantenham suficientes para realização da acumulação e da circulação desigual do dinheiro em seu estado puro (SANTOS, 2001).

\section{Nosso contexto comum...}

O meio ambiente e as discussões ambientais não poderiam ficar de fora desta lógica perversa. Eles passam, cada vez mais, a ser incorporados, não somente pelo capital que degrada, mas pela suposta ação sustentável do mesmo que pleiteia "salvá-los”. Estabelece-se na verdade outra forma para consumi-los.

Sob esse ponto de vista devemos, desde já, esclarecer que nosso posicionamento é amplamente favorável às discussões socioambientais e à constituição de uma ética ambiental que sejam, ao mesmo tempo, uma utopia ${ }^{2}$ e uma “cultura”, examinando as condutas destrutivas e predatórias

\footnotetext{
2 Sobre a utopia, Canclini (1996, p. 263-264) afirma que faz parte da vida social enquanto "dispusermos de uma certa emancipação, ou ao menos tivermos vontade de que a emancipação e a renovação do real continuem fazendo parte da vida social". Outro autor que nos fornece uma reflexão acerca da utopia é Santos (2001, p. 332) ao afirmar que "por utopia entendo a exploração, através da imaginação, de novas possibilidades humanas $e$ novas formas de vontade, e a oposição da imaginação à necessidade do que existe, só por que existe, em nome de algo radicalmente melhor por que vale a pena lutar e a que a humanidade tem direito. A minha versão de utopia é, portanto, duplamente relativa. Por um lado, chama a atenção para o que não existe enquanto (contra)parte integrante, mesmo que silenciada, daquilo que existe, ou seja, para aquilo que pertence a uma determinada época pelo modo como está excluído dela. Por outro lado, a utopia é sempre desigualmente utópica, dado que a sua forma de imaginar o novo é parcialmente construída por novas combinações e escalas daquilo que existe, e que são, na verdade, quase sempre meros pormenores, pequenos e obscuros, do que realmente existe. A utopia
} 
das sociedades industriais e pós-industriais, abrindo espaço para concepções preservadoras e preventivas que possibilitem repensar os usos e costumes da modernidade e seus impactos nas vidas humanas e ambientais.

A propósito da influência da cultura na relação do homem com seu meio ambiente, podemos nos remeter a Hall (1971), cujo trabalho aborda o espaço e o ambiente como produtos culturais. O autor, objetiva mostrar a cultura como uma dimensão oculta, “uma realidade escondida que escapa ao nosso controle e constitui a trama da existência humana” (Hall, 1971, p. 231). Para tanto, propõe o termo proxemie designando o conjunto de observações e teorias que têm por finalidade o uso que o homem faz do espaço e do ambiente.

Enquanto trama da existência humana, uma teia de significados, a Cultura assume, segundo Geertz (1989), uma dimensão semiótica. A conduta humana articula a cultura através de suas ações. Este autor advoga que:

Como sistemas de signos interpretáveis [...], a cultura não é um poder, algo ao qual podem ser atribuídos casualmente os acontecimentos sociais, os comportamentos, as instituições, ou os processos; ela é um contexto, algo dentro do qual eles podem ser descritos de forma inteligível, isto é, descritos com densidade (Geertz, 1989, p. 24).

Morin (2000a, p. 56), a respeito da diversidade cultural, afirma que “Diz-se justamente a cultura, diz-se justamente as culturas.”. O autor segue, apresentando a cultura como

constituída pelo conjunto dos saberes, fazeres, regras, normas, proibições, estratégias, crenças, idéias, valores, mitos, que se transmite de geração em geração, se reproduz em cada indivíduo, controla a existência da sociedade e mantém a complexidade psicológica e social. Não há sociedade humana, arcaica ou moderna, desprovida de cultura, mas cada cultura é singular. Assim, sempre existe a cultura nas culturas, mas a cultura existe apenas por meio das culturas.

Como afirmara Sposati (2001), é difícil estabelecer o que compõe um

requer, portanto, um conhecimento da realidade profundo e abrangente como meio de evitar que o radicalismo da imaginação colida com o seu realismo”. 
“padrão básico de qualidade de vida” que faça parte da cultura cidadã de todos, permitindo concluir que “...os fundamentos sobre um produto adequado ainda estão fortemente calcados em apreensões individuais, apreensões subjetivas, que são recortadas pelas técnicas de marketing e pela forte desigualdade social....” (Sposati, 2001, p. 16).

Há a necessidade do estabelecimento de uma cultura que passe, primordialmente, por “entender e buscar a difusão de condições básicas de qualidade de vida acessíveis para todos, no interior de experiências de defesa ambiental, como condição intrínseca e substantiva em sua concepção” (Sposati, 2001, p. 16).

É nesse aspecto que voltamos à questão do consumidor e do cidadão. Como o consumo mudou de figura ao longo do tempo, as empresas hoje não enredam o consumidor somente para assegurar a autonomia de uma produção. Atualmente, as empresas hegemônicas produzem o consumidor antes mesmo de produzir os produtos, ou seja, "um dado essencial para o entendimento do consumo é que a produção do consumidor, hoje, precede à produção dos bens e serviços” (Santos, 2001, p. 48).

Mesmo aqueles que se autodenominam de consumidores verdes, por mais que seu ativismo os queira convencer do contrário, não fogem a essa rede. Este consumidor verde não consegue deixar de ser

\begin{abstract}
o indivíduo que reproduz, em seu nível mais profundo, na sua estrutura de instintos, os valores e os padrões de comportamentos que servem para manter a dominação, enquanto a dominação se torna cada vez menos autônoma, menos "pessoal", mais objetiva e mais universal. O que 0 domina é o aparelho econômico, político e cultural, que se tornou uma unidade indivisível construída pelo trabalho social (Marcuse, 1970, p. 3).
\end{abstract}

Bem como já abordara Marcuse (1996, p. 3), “psicologicamente, é só isso o que aqui nos preocupa, a diferença entre dominação e liberdade está se tornando menor”. Dá-se pelo consumismo e pela competitividade um esquecimento da distinção que é necessária existir entre o sujeito consumidor e o sujeito cidadão. 
De acordo com Ianni (2002, pp. 28-29),

no curso dos jogos das forças sociais e das formas de sociabilidade que se formam e transformam, o indivíduo é levado à massificação e ao consumismo, de permeio aos contrapontos: realização e alienação, bem-estar e desespero, liberalismo e socialismo. À medida que se desenvolvem os meios de comunicação e a cultura de massa, bem como a indústria cultural, são muitos os que são levados a viver alheios à idéia e prática do espaço público, visto como instituição primordialmente política ou ideal de emancipação ou felicidade, transfigurando-se em membros da multidão de solitários. Assim, entre os vários e cruciais dilemas com os quais se defrontam indivíduos e coletividades, em todo o mundo, torna a colocar-se a interrogação sobre "o indivíduo", buscando-se saber: quem é; onde está; como se forma; se dispõe de condições para realizar-se; por que continua a ser problemático; trata-se de uma figura em declínio; continua a dizer to be or not to be; ou já chegou à conclusão de que never more.

Entendemos que o consumismo não pode (e não deve) ferir os princípios de cidadania e, tampouco, gerar contextos problemáticos para as gerações futuras. Dessa forma, concordamos com Edgar Morin quando, ao analisar a condição humana, considera a importância da "formação de uma consciência humanística e ética de pertencer à espécie humana, que só pode ser completa com a consciência do caráter matricial da Terra para a vida, e da vida para a humanidade” (Morin, 2000a, p. 39).

Cabe inferir, que ao tratarmos de cidadania não falamos de uma visão ingênua da mesma. Temos em mente suas múltiplas dimensões e estruturações em sociedades capitalistas intituladas como democráticas. Nestas sociedades, o conteúdo contraditório e ambivalente da problemática da cidadania reflete a existência de um terreno de disputa social, política, econômica e cultural, envolvendo restrições, exclusões, inclusões e negociações.

Assim, como apontara Afonso (2001), a cidadania se transforma em uma categoria dinâmica e inacabada. Para este autor,

se por um lado, as políticas sociais e educacionais, em um contexto capitalista, podem ser interpretadas como instrumentos de controle social e como formas de legitimação da ação do Estado e dos interesses das classes dominantes, por outro lado, 
também não deixam de poder ser vistas como estratégias de concretização e expansão dos direitos sociais, econômicos e culturais, tendo, neste caso, repercussões importantes na melhoria das condições de vida dos trabalhadores e dos grupos sociais mais vulneráveis às lógicas da exploração e da acumulação capitalistas (Afonso, 2001, p.22).

Também toca esclarecer, ao tratarmos da participação dos cidadãos nos processo sociais, que atentamos para o modo como a ideia de participação foi igualmente desvirtuada pelos paradigmas ${ }^{3}$ e racionalidades hegemônicos presentes na ciência e no pensamento clássicos, causando confusões que ora tornaram a participação instrumento de objetividade racional e coletiva, ora tornaram-na lugar de preocupação com a individualidade e com a afetividade (Sawaia, 2001).

Essa situação se agrava quando verificamos que até no denominado movimento ambientalista, em troca do direito de participar da elaboração de políticas setoriais, manifestam-se posições de aceitação e perda da radicalidade a respeito de premissas básicas, por parte dos integrantes e ativistas ao empreenderem e incorporarem às "ações verdes” provindas de agentes do mercado (firmas e empresas) que, de modo oportunista, utilizam como "bandeira" atos pontuais de preservação associados, geralmente, à explorações, ditas racionais, dos recursos naturais.

Como apontara Alexandre (2000), deu-se a banalização da problemática socioambiental, que passou a ser anexada para justificar e premiar os empreendedores do chamado ecobussiness, principalmente quando estes “empresários verdes” se deram conta que os investimentos milionários mundiais, envolvendo o controle ambiental já faturavam, na década de 1990, no mundo, mais que a indústria bélica e, no Brasil passaram do bilhão por ano. O autor afirma que:

3 Para Morin "O paradigma desempenha um papel ao mesmo tempo subterrâneo $e$ soberano em qualquer teoria, doutrina ou ideologia. O paradigma é inconsciente, mas irriga o pensamento consciente, controla-o e, neste sentido, é também supraconsciente. Em resumo, o paradigma instaura relações primordiais que constituem axiomas, determina conceitos, comanda discursos e/ou teorias. Organiza a geração deles e gera a geração ou a regeneração.”. Morin, E. Os sete saberes necessários à educação no futuro. São Paulo: Cortez , 2000(b), p. 26. 
na pauta dos conflitos e discussões dos maiores problemas sócio-ambientais, o cerne da problemática ambiental, entretanto, não é tratado, ou seja, mudanças drásticas nos valores morais e estilos de vida. Sempre transparece que arranjos setoriais e particularizados darão respostas à crise socioambiental generalizada que é conseqüência do modelo de desenvolvimento econômico neoliberal predominante no mundo globalizado e requer sempre mais produção com mais estímulo ao consumo, gerando um processo de alienação no trabalho com repercussão na cultura, no lazer etc (Alexandre, 2000, p. 30).

Nesse contexto novo, ainda dificilmente interpretado e desvendado a relação da sociedade com a natureza permanece obscurecida. O distanciamento entre o homem e a natureza impede a visualização daquilo que todos buscam. Acontece a incorporação da natureza e a sua redução a um recurso natural, a uma mercadoria, que em última instância passa a ser adquirida sob o signo da apropriação com qualidade, servindo como uma "luva" para os discursos técnico-científicos atualizados, viabilizando a geração "racional” da riqueza, assim como, novas pesquisas "politicamente corretas" sobre esses recursos.

Observamos que uma série de vieses são omitidos nos discursos sobre o meio ambiente, sendo que a corrida pela matéria-prima e a materialização de novas necessidades transformam tudo que é ambiental em mercadoria. O entendimento adequado somente será possibilitado pela análise crítica dos mesmos. Caso contrário, persistirá o domínio da visão mercadológica, na qual toda a natureza se torna passível de utilização direta ou indireta, ativa ou passiva, econômica ou política.

Não que haja uma mundialização da natureza, mas há uma natureza unificada em uma economia mundializada. Esta mundialização é econômica e é, por sua vez, controlada pelos atores hegemônicos em escalas estranhas ao lugar, causando impactos verticais - verticalidades ${ }^{4}$ - e destruindo, ou tentando destruir e comandar as ações solidárias ao lugar -

\footnotetext{
${ }^{4}$ Segundo Santos "a idéia de verticalidade vem desses vetores que se instalam nos lugares e que pouco se importam com o que está em seu entorno. É o que corresponde, sobretudo, às ações das empresas globais.” Santos, M. Território e Sociedade - entrevista com Milton Santos. São Paulo, Ed. Fundação Perseu Abramo, 2000, p. 53.
} 
horizontalidades 5 . Parece que a única base reativa é o espaço compartilhado no cotidiano, ou seja, o lugar. "Lugar este onde os homens estão juntos, sentindo, vivendo, pensando, emocionando-se” (Santos, 1996, p. 258).

Como agravante, Morin (2000a) assinala que nos círculos científicos, ainda somos vítimas da enorme disjunção natureza/cultura, animalidade/humanidade, sempre desmembradora de nossa natureza de ser vivo, estudada pela biologia, e de nossa natureza física e social, estudada pelas ciências humanas e que a revolução das recomposições multidisciplinares está longe de ser generalizada. Estas fragmentações são derivadas, entre outros aspectos, da racionalidade científica baseada numa concepção positivista e cartesiana a respeito da natureza "como sendo uma espécie de mecanismo passivo, eterno e reversível, passível de se deixar desmontar e depois relacionar sob a forma de leis.” (Fonseca, 2001, p. 40).

Decorre que, apesar de todos os progressos econômicos e materiais, crescem também as desigualdades e desequilíbrios socioambientais. A própria tecnociência, "mola propulsora" do período atual, seria um fator fundamental no agravamento do cenário de crise contemporânea ao comandar o problema do desenvolvimento e o problema da civilização, além de determinar a perspectiva frente à explosão demográfica e à ameaça ecológica. Para Milton Santos (1996), ao mesmo tempo em que se instala uma tecnosfera ${ }^{6}$ (através do meio-técnico-científico informacional) cria-se, paralelamente, uma psicosfera ${ }^{7}$. Ambas - tecnosfera e psicosfera - são locais, mas constituem o produto de uma sociedade bem mais ampla que o lugar. São produtos do artifício, criando tecnificações além de sentidos e subjetividades.

Apenas o simples controle da marcha da tecnociência não daria fim à tragédia do desenvolvimento e ao problema civilizacional, não poria fim à

5 Como horizontalidade apreende-se "o resultado da vizinhança, da coabitação, da coexistência do diverso...”. Santos, M. Ibidem.

6 Dependente da ciência e da tecnologia e adaptada aos mandamentos da produção e da troca, traduzindo interesses distantes, substituindo o meio natural e o meio técnico, e aderindo ao lugar como uma prótese.

${ }^{7}$ Na qual ideias, crenças, paixões produzem um sentido, compondo o ambiente, o entorno da vida ao fornecer regras à racionalidade ou estimular o imaginário. 
cegueira produzida pelo pensamento fragmentado, parcelar e redutor, além de não suprimir aos problemas demográficos e ecológicos. Este fato se dá, como observado por Morin \& Kern (1996), em razão da tecnociência depender do conjunto da civilização que hoje, por sua vez, depende da tecnociência. A quebra do isolamento na construção do conhecimento é, para os autores, fundamental no tratamento do problema que, por sua vez, deve ser conduzido de maneira diversificada segundo as regiões do planeta. Infelizmente, nosso sistema de ensino inserido em todo este painel de fragmentações e disjunções, também não vem corrigindo esses “desenvolvimentos”, ao contrário, obedece a eles. A argumentação de Edgar Morin fundamenta tal crítica ao captar que

o que agrava a dificuldade de conhecer nosso Mundo é o modo de pensar que atrofiou em nós, em vez de desenvolver, a aptidão de contextualizar e de globalizar, uma vez que a exigência da era planetária é pensar sua globalidade, a relação todo-partes, sua multidimensionalidade, sua complexidade (...) (Morin, 2000b, p. 64).

Portanto, identifica-se que a questão do ambiente é posta em evidência justamente quando do aparecimento do meio técnico-científico, através do qual a sociedade industrializada se transforma até alcançar um novo momento. Na opinião de Santana (1996, p. 52), “é possível avistar a importância que as potências político-econômicas dão ao conhecimento técnico-científico (e tecnológico) das matérias naturais do mundo, tanto por suas riquezas como pelas expectativas e possibilidades de virem a gerar riqueza”.

Essa ótica de desenvolvimento produz a atomização dos indivíduos, que perdem solidariedades antigas sem adquirirem novas, a não ser anônimas e administrativas. Vemos a ampliação artificial do distanciamento entre a sociedade (homem) e a natureza (ambiente).De acordo com Santos (1994), a história do homem sobre a terra é a história de uma ruptura progressiva entre o homem e o entorno.

Com a evolução da história humana, a economia mundializada desfaz os modelos particulares de associação do homem com a natureza. Todas as 
sociedades adotam, de forma mais ou menos intensa, um único modelo técnico que se sobrepõe à multiplicidade de recursos naturais e humanos. A partir desta enorme mudança, a natureza continua sendo una, porém, foi socialmente se fragmentando e, é agora unificada pelos Estados, firmas e classes hegemônicas (Santos, 1996).

Instala-se o reino anônimo do dinheiro em estado puro ${ }^{8}$, que progride, associado ao reino anônimo da tecno-burocracia. Estes estipulam os lugares sociais com ações diferenciadoras e desintegrantes através do espírito da competição e da fabricação do sucesso. Por esta linha de raciocínio, dentro do atual sistema da natureza, o homem se afasta da possibilidade de relações totalizantes com o seu próprio entorno. O que parece estar em suas mãos é concreto, mas não para ele, são partes desconexas do todo. Tudo é intermediado pela técnica e por seus agentes. Para que estes possam ser alcançados o homem produtor subordina-se ao homem consumidor, aquele ao produto vendido no mercado, e esse último às forças libidinais cada vez menos controladas, num processo em que se cria o consumidor para o produto e não o produto para o consumidor. É este homem que perde a identidade com seu entorno.

Em paralelo às fragmentações surgem tentativas humanas de recomposições. Assim sendo, a natureza ressurge por meio dos desejos passíveis de consumo através das decorações dos lares, da busca do descanso, dos paraísos ecoturísticos, atingindo um afã ecológico que acentuou a procura do "natural” em todos os domínios, chegando até a alimentação. Nem as paixões escaparam. Nelas tanto pessoas, quanto lugares e paisagens consomem e são consumidas depressa criando, paradoxalmente, amores que se enfraquecem ao se multiplicarem, se fragilizando com o tempo, de tal modo, que novos amores matam os antigos.

\footnotetext{
8 Segundo Milton Santos (2001, p. 56) "O consumo, tornado denominador comum para todos os indivíduos, atribui um papel central ao dinheiro nas suas diferentes manifestações; juntos, o dinheiro e o consumo aparecem como reguladores da vida individual. O novo dinheiro torna-se onipresente (...) O resultado objetivo é a necessidade, real ou imaginada, de buscar mais dinheiro.”
} 
Neste sentido, Kehl (1999) constata que:

o imperativo do gozo substitui a interdição do excesso, e embora gozar plenamente seja impossível para o ser humano, é isto o que o supereu, reproduzindo os discursos dominantes e os valores em circulação, exige dos sujeitos. (...) estamos diante dos efeitos produzidos pelo apagamento das diferenças. (...) mas não daquelas artificialmente mantidas, e sim das diferenças subjetivas, condição de nossa humanidade, de nossa incompletude humana, de nossa dependência em relação ao outro. (...) o cidadão ideal da sociedade de consumo acredita que possui e domina o objeto de desejo, uma série infindável deles, e que portanto está livre da condição de desejar o desejo do outro. (...) quanto às diferenças de direitos, de privilégios e de distribuição de riquezas, bem - a suposição de uma anulação geral da semelhança na diferença nos torna cada vez mais indiferentes a elas (Kehl, 1999, p. 94-95).

A grande questão é que uma forma social não existe descolada de um sistema simbólico e de uma totalidade social nas quais faça sentido. Os sujeitos medem o valor das mercadorias que intercambiam e se medem uns pelos outros, assim como, aferem seu próprio valor pelo valor das mercadorias que trocam (Kehl, 1999). Neste processo, com certeza, esquecem o que as mercadorias escondem. O consumo instala sua fé por meio dos objetos, que nos cercam em nosso cotidiano pela presença imediata, pela promessa ou esperança de obtenção.

Em relação aos avanços tecnológicos, paradoxalmente, no mundo capitalista continuam sendo desenvolvidos novos produtos e reinventados outros que jogam na atmosfera uma quantidade infinita de gases e objetos poluentes. Exemplo disso são os celulares “sempre” de última geração que dão lugares a outros que, até “ontem”, eram, também, de última geração. Esses aparelhos “top de linha” encantam os olhares dos consumidores, sobretudo dos jovens que desejam e exigem de si mesmos o sentimento de estar sempre na moda para que se sintam incluídos no seu meio. O que impera, nesses casos que são recorrentes em nossa sociedade, é a lógica do consumo não pela necessidade, mas pelo desejo de consumir.

Para Baudrillard (1995) acomoda-se, com a sociedade de consumo, uma sociedade de aprendizado do consumo, condicionadora social do 
mesmo, criando um novo e específico modo de socialização contribuinte de um sistema econômico a produtividade alta, gerando o que Mészáros (1971) adjetivou como “uma sociedade de consumo que produz desperdícios”.

Em nosso país, segundo observado por Santos (1993), temos o denominado “consumidor mais-que-perfeito”, um não-cidadão, que às vezes se julga, através do voto, enquanto eleitor, um completo cidadão, embora seja impedido de realizar suas potencialidades como participante ativo e dinâmico de uma comunidade, constituindo-se, assim como, o consumidor, num “imbecil feliz”, conforme citado por Santos (1993, p. 41), a partir da alusão de Laborit (1973).

\section{Mudanças em curso...}

Como o cidadão imperfeito acaba alijado do entendimento do próprio quadro da vida, da natureza e do entorno humano, carregado de significações sobrepostas, devemos buscar o entendimento complexo desse quadro a fim de apreendermos que a capacidade de utilizar o território não apenas divide como separa os homens, ainda que eles apareçam como se estivessem juntos (Santos, 1993).

No mundo atual, o poder hegemônico capitalista se deslocou, se desterritorializou em extensão, ampliando seu domínio sobre o conjunto da vida social, econômica e cultural e, em intenção, infiltrando-se no seio dos mais inconscientes estratos subjetivos. Nesta teia enganosa, o indivíduo participa como usuário. Compromete-se a comprar o ar puro, a água pura, os bosques, ou a consumir a natureza artificializada e instrumentalizada ao extremo. Quem não pode pagar, inclusive por bens essenciais que deveriam ser públicos, fica excluído do gozo desses bens.

Todavia, por outro lado, é importante refletir sobre até quando e em que condições esses bens poderão ser, efetivamente, comprados. Diversas pesquisas que vêm sendo realizadas no cenário mundial nos mostram que os chamados recursos naturais estão sendo, gradativamente, reduzidos. Instalase um quadro de escassez. 
Há a materialização constante de novas necessidades, inclusive redescobrindo a natureza, visando obter uma suposta vida digna e humanizada, que se estabelece pela tentativa de transformá-la em mercadoria, assim como, criar novos mercados e usuários. O homem produz um “espaço natural” artificial, principalmente nas grandes cidades. Mas como esta produção, com base numa racionalidade hegemônica, está a serviço de um conjunto de ideias e agentes hegemônicos, na escala do lugar e nos diferentes lugares produzem-se, em paralelo, a carência e a escassez. Santos (2001, p. 129) considera que "a situação contemporânea revela, entre outras coisas, três tendências: uma produção acelerada e artificial de necessidades; uma incorporação limitada de modos de vida ditos racionais; uma produção ilimitada de carência e escassez”. Para os “não-possuidores”, viver na escassez gera conflitos e até guerras. A cada dia enfrentam uma nova experiência de escassez. Individualmente não têm força de negociação, e sua sobrevivência está baseada na renovação imperativa de suas experiências, baseadas em bens infinitos, tais como a solidariedade e a liberdade.

Ocorre que hoje, não somente os pobres sentem no cotidiano a experiência da escassez. A chamada classe média vem passando, nos últimos anos, de forma progressiva, uma situação existencial cada vez mais incerta no que diz respeito ao emprego, ao salário, à moradia, à saúde, ao lazer, à aposentadoria, à qualidade de vida e ao endividamento constante que colocam em risco sua visão de futuro sempre emergente. Como seus privilégios de consumo são banalizados no corpo social fragmentado, as soluções oferecidas pelo mercado e pelo Estado não destacam as classes médias como determinantes para a partilha do poder. Enquanto “consumidores-mais-que-perfeitos”, tendem a culpar, por sua situação nova e desconfortável, aqueles que, como o mercado e a mídia, possibilitaram sua herança existencial dantes privilegiada, os políticos. Assim, como reflexo, acabam por desejar menos política, resultando menos participação.

Pela intensificação destas contradições, entendemos que o período atual, carece de análises mais complexas, pelas quais devemos superar a 
visão da participação como um fenômeno dicotomizado entre razão e emoção, entre público e privado ou como algo produzido e vivido fora do sujeito. Ao falarmos em participação estamos:

nos posicionando sobre concepções de sociedade, de cidadania, de ética e de justiça, bem como sobre educação popular e movimentos sociais, desigualdade e exclusão social. (...) falar que o ser da participação é definido fora dele, na sociedade, e que, portanto, varia historicamente, não é afirmar que a participação está fora do indivíduo, independente da subjetividade e que é, ontologicamente, um fenômeno objetivo. (...) o ser da participação é definido na sociedade e na subjetividade. (...) o ato de participação do sujeito é determinado pelos modelos dominantes de participação social, mas é organizado num contexto de subjetividade como experiência existencial, impregnada de emotividade (Sawaia, 2001, p. 120 e 123).

Segundo Santos (2001, p. 138) “a atual experiência da escassez pode não contribuir imediatamente à desejável expansão da consciência”. Mas passada a fase inicial de manifestações individualistas, um momento posterior, com reflexões mais aprofundadas no tecido social, pode gerar um nível qualitativo superior, caracterizado por apreensões mais sistêmicas do processo social e da totalidade em movimento, instalando um processo importante de busca de novos valores. Como efeito, apesar de um dos elementos ao mesmo tempo ideológico e empiricamente existencial da globalização ser a centralidade do consumo, as atuais relações instáveis de trabalho, os problemas ambientais, a expansão do desemprego, o crescimento das violências e a baixa do salário médio, entre outros, contrastam em relação à multiplicação dos objetos e serviços, à degradação das relações pessoais e ambientais, tornando improvável o acesso aos mesmos, assim como, impossível suas obtenções para grande parte da população.

O processo de tomada de consciência é diferenciado segundo os lugares, as classes sociais ou situações profissionais e os indivíduos. Todavia, para qualquer mudança neste estado de coisas, todo cuidado é pouco, pois a consciência da diferença pode conduzir simplesmente à defesa individualista do próprio interesse, sem alcançar a defesa de um sistema 
alternativo de ideias e de vida. Não vamos aqui confundir individualismo e individualidade ${ }^{9}$. Tratamos de uma construção social baseada na existência de individualidades fortes que ultrapassam a barreira da práxis repetitiva e se instalam em uma práxis libertária ${ }^{10}$.

Por esse caminho, nos aproximamos de ideias relacionadas a uma abordagem renovada da ciência e de um entendimento mais amplo do movimento do mundo. Abre-se o olhar, menos distanciado, sobre as questões ambientais enquanto questões sociais, convidando os sujeitos a participarem dos conflitos e das soluções com “seus” conflitos e com “suas” soluções. Supõe-se uma cultura emancipatória, tal como aludido por Boaventura de Souza Santos (2001), segundo a qual os sujeitos pertencem à subjetividades e à solidariedades coletivas, centradas na construção de um paradigma social emergente, firmado no estabelecimento de um senso comum emancipatório. Tal projeto somente dar-se-á pela construção e uso estratégico de técnicas que objetivem conhecer quer o senso comum dos envolvidos, quer as alterações desse senso comum ao longo do processo na direção da emancipação. O senso comum emancipatório requer um novo conhecimento, que soma o saber acadêmico com o saber popular, provocando um novo senso comum argumentativo do desejo de mudança.

Em consonância com essas ideias, Kostrowichi (1988) já atentava que, qualquer que seja nosso pensamento sobre o problema ambiental, devemos ter em mente que este problema é, antes de tudo, social. Nesse sentido fazse mister, por um lado, o conhecimento das fontes psicológicas de avaliação relacionadas ao ambiente, aos hábitos culturais, à receptividade, à informação, e de outro, às motivações biológicas das escolhas. O

9 Não advogamos valorizar perspectivas individualistas. Ao contrário, foge-se do individualismo enquanto momento ilusório de liberalização das individualidades para melhor dominá-las através do mercado e de outros instrumentos de dominação. Como apontara Sawaia (1998, p. 100), realizada desta forma, a ação individualizadora cria um "Momento que reconhece a multiplicidade entre os homens e a liberdade de ser diferente, mas impede a comunicação entre os diferentes e trabalha num sentido de esmagamento uniformizante.” Sawaia. B. B. A falsa cisão retalhadora do homem. In: Martinelli, M. L., On, M. L. R. \& Muchail, S. T. (Orgs.) O Uno e o Múltiplo nas Relações entre as Áreas do Saber. São Paulo, Cortez, 1998, p. 96-109 .

${ }_{10}$ Ver práxis em Lefebvre, H. Critique de la vie quotidienne. Paris: Éditions l'Arche , V. I: “Introduction”, 1958, p. 240. 
conhecimento das bases psico-fisiológicas tem um papel particularmente importante no estudo dos problemas ambientais, porque sem integrar os aspectos psicológicos e sociais no modelo de compreensão e "otimização" do meio, nos arriscamos a construir ou propor soluções e mudanças que, embora sejam plenamente justificáveis do ponto de vista científico, serão recebidas "friamente" ou mesmo tratadas como "desumanas" e, por conseqüência, não serão aceitas pela sociedade. Esta visão aproxima-se da elaborada por Guattari (1990) para quem é essencial que se organizem novas práticas micro-políticas e micro-sociais, novas solidariedades, uma nova suavidade, juntamente com novas práticas estéticas e novas práticas analíticas das formações do inconsciente.

A propósito, Guattari (1990) tem a convicção de que a questão das subjetividades colocar-se-á, progressivamente, à medida que se desenvolverem as máquinas produtoras de signos, de imagens, de sintaxe, de inteligência artificial, disso decorrendo “uma recomposição das práticas sociais e individuais que agrupo segundo três rubricas complementares - a ecologia social, a ecologia mental e a ecologia ambiental - sob a égide ético-estética de uma ecosofia” (Guattari, 1990, p. 23).

Outro ponto destacado no trabalho de Kostrowichi (1988) se refere à

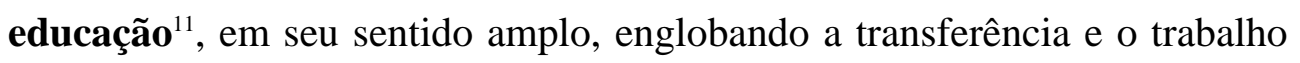
com as informações sociais feitas por meios e formas dinâmicos, partindo de saberes pertinentes que envolvam todo sistema educacional, indo para além dele, concentrando-se sobre questões fundamentais, críticas e não periféricas.

\footnotetext{
11 Agrada-nos especialmente a acepção cunhada por Madeira \& Alloufa sobre educação, em função de sua articulação à cultura, “.... educação é um processo de construção pessoal e social das representações dos indivíduos e grupos. Ela é a relação interpessoal e grupal do ensinar e aprender, na interação de um processo histórico, contextualizado em um espaço e um tempo. Isto abre outra via para a consideração da cultura, em sua relatividade e em sua universalidade.”. Madeira, M.C. \& Alloufa, J. Representações sociais e Educação: que relação é esta ? In: II Colóquio Franco-Brasileiro Educação e Linguagem, Natal (RN), 1996. Anais... UFRN - Université de Caen. EDUFRN (RN), p. 11-15, 1997. Ainda segundo Madeira, neste processo "... a cultura e o conhecimento são continuamente, transmitidos e (re)construídos, envolvendo a totalidade do sujeito em suas relações com o(s) outro(s).". Madeira, M. C. Representações Sociais e Educação: importância teórico-metodológica de uma relação. In: MOREIRA, A. S. P. (org.) Representações Sociais: teoria e prática. João Pessoa, Ed. Universitária UFPB, 2001, p. 123-144.
} 
Isto também vale para atentarmos em não nos deixar conduzir por discursos ambientais que utilizam a mesma lógica dos atores hegemônicos, tentando "provar" e "medir” o valor da natureza e dos recursos naturais. Um exemplo disso pode ser visto na reportagem "O valor do verde" ${ }^{12}$ que apresenta uma pesquisa sobre os benefícios proporcionados aos seres humanos pela ação de dezesseis grandes ecossistemas terrestres estudados. Inferem-se valores que remontam a casa dos 33 trilhões de dólares anuais relativos aos benefícios desses ecossistemas sobre as diversas atividades humanas, incluindo as atividades produtivas mais modernas. Não obstante as cifras sejam gigantescas, equivalendo a quase duas vezes toda a riqueza produzida no mundo anualmente, seus impactos e influências foram mínimos e os seus resultados perderam-se num turbilhão de cifras e notícias que cotidianamente assistimos sobre a economia e sobre a ecologia, sem que haja qualquer correspondência com possíveis mudanças nas ações que, efetivamente, possam promover a diminuição da degradação ambiental e dos desajustes socioambientais presentes em nossa sociedade.

Concordamos com o posicionamento apresentado por Morin (2000a), segundo o qual, temos a necessidade de fundar "princípios para o conhecimento pertinente" que sejam capazes de apreender os problemas globais e fundamentais para neles inserir os conhecimentos parciais e locais. É preciso ensinar e aprender os métodos que permitam estabelecer as relações mútuas e as influências recíprocas entre as partes e o todo em um mundo complexo. Como afirmara Guattari, "menos que nunca a natureza pode ser separada da cultura, e precisamos aprender a pensar "transversalmente" as interações entre ecossistemas, mecanosfera e Universos de referências sociais e individuais” (GUATTARI, 1990, p. 25).

Caso contrário, de pouco adiantará apostar no milagre dos volúveis “consumidores verdes"13 que ascenderam e cresceram em diversos lugares do mundo, principalmente nos países ricos, juntamente com a propaganda

\footnotetext{
${ }^{12} \mathrm{O}$ valor do verde: estudo calcula em cifrões os benefícios que alguns ecossistemas geram para a humanidade.Thomas Traumann - Revista Veja, 04/06/97, p. 80-81.

${ }^{13}$ Cairncross, F. Meio ambiente: custos e benefícios. São Paulo: Nobel, 1992, 267p.
} 
verde. Muitas dessas propagandas são feitas para aproveitar o consumismo verde sem que realmente os produtos “enverdecidos” comprovem seus efeitos ou benefícios para o ambiente ou para seus usuários. Na verdade, o “bom comportamento” ou a "boa reputação” verde, vem se tornando apenas mais um dentre uma série de indicadores de qualidade que consumidores e empresas procuram quando compram ou quando vendem. Não há como acreditar que estes consumidores possam ser, fora da lógica de sua transformação em cidadãos, indivíduos que escapem à racionalidade econômica e à ideologia dominante da sociedade industrial e pós-industrial de consumo. Como apontara Portilho ${ }^{14}$, "o consumo verde, ao contrário de promover um enfrentamento da questão da esgotabilidade dos recursos naturais, atende à continuidade dos privilégios da sociedade afluente”, sendo claro que o consumo verde assume, em função da ameaça ecológica alardeada, um caráter de consumo com obrigação “cívica”. Este constrangimento difere, diametralmente, da recuperação do cidadão, através da participação, como ser consciente de seu pertencimento à coletividade, de possuidor de identidade (individual e coletiva) e de direitos civis, políticos e sociais. Sinaliza-se na direção de um modelo cívico autônomo, que não se subordina ao modelo econômico ${ }^{15}$, partindo do cidadão para a economia e não ao contrário (Santos, 1993).

Cabe sublinhar que o primeiro passo nesse projeto já está em curso para alguns pensadores. Baseia-se na perspectiva de estabelecimento de uma cultura emancipatória. Supõe levar a cabo a subjetividade emergente ${ }^{16}$, na

\footnotetext{
14 Portilho, F. Consumo "verde", democracia ecológica e cidadania: possibilidades de diálogo ? Disponível na Internet no sítio: http://www.rubedo.psc.br/Artigos/consumo.htm 15 "O que condena o sistema de valorização capitalístico é seu caráter de equivalente geral, que aplaina todos os outros modos de valorização, os quais ficam assim alienados à sua hegemonia" Guattari, F. Ibidem, p. 51.

16 De acordo com Santos, B. S. 2000, Ibidem, simultaneamente individual e coletiva, constituída por um conhecimento prudente para uma vida decente, que vive na fronteira, desenvolvendo novas formas de sociabilidade, hibridizando-se, de forma criativa, imaginária e descontínua como o barroco a partir de referências culturais solidárias e emancipatórias do Sul. Convém mencionar que esta interpretação aproxima mais ainda os dois Santos - Boaventura e Milton - para quem a centralidade da periferia, a ruptura com o centro do sistema, sairão do Sul, dos países subdesenvolvidos, numa outra globalização, dos "de baixo", que permitirá uma revanche da cultura popular sobre a cultura de massa, assemelhando-se à valorização do barroco e do cotidiano vivido solidariamente.
} 
qual os sujeitos se caracterizam pela presença efetiva, através da defesa de propostas com argumentos, com capacidade de decisão e pela construção coletiva. Esta cultura emancipatória se funda, por conseguinte, em formas novas de conhecimento tornadas possíveis através de solidariedades coletivas. Implica como princípios a coragem de construir uma utopia e reinventar um mapa emancipatório que não seja mais um mapa de regulação e, ao mesmo tempo, reinventar uma subjetividade individual e coletiva capaz de usar e querer usar esse mapa.

O mapa das emancipações contrapõe nos espaços estruturais ${ }^{17}$ o modo como os mesmos estão regulados na atualidade. Especificamente, em relação aos espaços da produção, do mercado e da cidadania, Boaventura de Souza Santos (2001) ${ }^{18}$ aponta a constituição da produção ecossocialista, a valorização das necessidades humanas e do consumo solidário e o surgimento de uma democracia radical ou do socialismo-como-democraciasem-fim ${ }^{19}$.

\section{Sem esperar pelo fim...}

Como nos disse Ortega y Gasset (2001) "Yo soy yo y mi circunstancia y si no la salvo a ella no me salvo yo" ${ }^{20}$. Compete frisar que todas as mudanças necessárias só podem se dar no mundo, do qual tomamos parte, não apenas como uma criação do espírito, pois ele, o mundo, existe concretamente (Santos, 2000). É dele que devemos partir para construir outra coisa, ou seja, outro mundo; um mundo melhor. O seu movimento faz com que, no campo do conhecimento, cada saber se relacione com os demais e com que as disciplinas se transformem. Caminhamos para superar a inadequação cada vez mais ampla, profunda e grave entre os saberes

\footnotetext{
17 São eles: o espaço doméstico, o espaço da produção, o espaço de mercado, o espaço da comunidade, o espaço da cidadania e o espaço mundial. "Estes espaços são os conjuntos mais elementares e mais sedimentados de relações sociais nas sociedades capitalistas contemporâneas”. Santos, B. S. Ibidem, p. 272.

18 Santos, M. 2000, Ibidem.

19 Para aprofundar, ver Santos, B. S. 2001, Ibidem, capítulo 6, p. 229-344.

${ }^{20}$ Ortega y Gasset, J. Meditaciones del Quijote. Madrid: Alianza, 2001, 167p.
} 
separados, fragmentados, compartimentados entre disciplinas, e, por outro lado, realidades ou problemas cada vez mais polidisciplinares, transversais, multidimensionais, transnacionais, globais, planetários.

Com o processo de informação, de inserção, de apreensão, de busca do mundo através das disciplinas, todas mantendo sua relação com mundo, é que se pode formar a metadisciplina, uma "vontade de filosofar nas disciplinas”. É o mundo que permite que se estabeleça um discurso inteligível, um canal de comunicação e solidariedade entre os saberes e os sujeitos dos saberes. É a possibilidade de um discurso intercambiável que permite estabelecer a metadisciplina no sentido da fertilização mútua dos conceitos que não são impenetráveis. É nesta “religação dos saberes” (Morin, 2001) através da reforma paradigmática do pensamento, religando e diferenciando, contextualizando práticas sociais em curso, que poder-se-á explicitar a necessidade de superação dos problemas atuais, fortificando a aptidão em interrogar e em ligar o saber à dúvida, desenvolvendo a aptidão para integrar o saber particular a própria vida e não somente a um contexto ou tendência global, a competência para os sujeitos colocarem a si mesmos os problemas fundamentais de sua condição e de seu tempo.

Tudo isto depende, porém, da possibilidade de fazermos parte do que é discutido, pois compreendemos quando realmente fazemos parte do que é compreendido. É assim que nos sentimos integrantes da Teia da Vida. Esta vida assume de fato valor absoluto na medida em que acreditamos e agimos firmados na convicção de que todos os seres que existem partilham conosco da experiência da visa, possuindo todos eles sentido e valor em si mesmos (Brandão, 2005). O autor nos insere como partícipes do círculo do dom da vida, na rede da existência do dom da vida. Nessa rede emaranhada, somos frutos e sujeitos da experiência da vida, em contato e com-vívio permanente e diversificado com unidades diferenciadas de partilha de vida. Portanto somos nós mesmos integrantes de toda a vida. É essa vida que cria e recria a Terra na Terra, dando-lhe também a vida.

O que Carlos Rodrigues Brandão nos convida a concluir é que na teia 
de trocas da vida, tudo que existe está situado dentro, entre, e em algum tipo de relacionamento com. Portanto são os relacionamentos, os diálogos e as interconexões que dão a vida uma consciência reflexiva de e sobre si mesma.

Para tanto, conforme argumenta Boff (2003), há a necessidade da confluência das diversas éticas baseadas no utilitarismo social, no discurso comunicativo e da justiça, nas tradições religiosas, na defesa dos pobres e excluídos com aquelas fundadas na dignidade terrestre. Segundo o mesmo autor, tal confluência necessita, por sua vez, que levemos em consideração o cuidado, como modo de ser concreto no mundo com os outros, descobrindo o mundo como valor, fazendo surgir o sentimento da responsabilidade. Além dele, deve haver a solidariedade, compreendida e calcada na interdependência entre os seres na origem e nos destinos comuns, sob um entendimento ôntico e político. Outro ingrediente indispensável é a responsabilidade, pela qual o ser humano se faz co-responsável, juntamente as forças diretivas do universo e da natureza, pelo destino da humanidade e de sua casa comum, ou seja assume-se a responsabilidade pelo meio ambiente, pela qualidade de vida de todos os seres e pelas gerações atuais e futuras. Outro componente importante, sem o qual o projeto de confluência não se estabelecerá, diz respeito ao diálogo, permitindo a construção coletiva da solidariedade universal em todas as frentes e níveis, entendendo que o ser humano aprende moralmente à medida que convive, relaciona-se e intercambia continuamente com os diferentes. Alia-se a estes pensamentos práticos a emergência da com-paixão e da libertação pela participação no sofrimento e no padecimento do Outro e nas suas lutas de libertação, colaborando para que Este supere a ideia de totalidade social como dada, principalmente na sua condição de exclusão e de discriminação. Tal emergência situa-se em sintonia com a ampliação gradativa da capacidade de pensarmos, todos nós, transversalmente, de forma holística ou hologramática, conforme já advogaram Morin \& Kern (1996), inter-retrorelacionando os fenômenos e culturas, tomando parte do jogo e da dinâmica das partes e do todo, valorando as diferentes morais, enquanto 
complementares, guardando sentido de unidade e totalidade complexa e orgânica. Sob este aspecto temos sim o privilégio, mas também a necessidade e a oportunidade única de, como seres humanos, partilharmos da consciência reflexiva e auto-reflexiva, que nos permite entender ou interpretar que nossas experiências naturais e culturais poderão ter existência prolongada se também partilharmos do amor, da harmonia e da paz, ou seja, de sentimentos, valores e razões que dão sentido e densidade à vida.

\section{Referências}

AFONSO, Almerindo Janela. Reforma do Estado e Políticas Educacionais: entre a crise do Estado-nação e a emergência da regulação supranacional. Educaşão \& Sociedade, Campinas, v. 22, n. 75, p. 15-32, 2001.

ALEXANDRE, Agripa Faria. A perda da radicalidade do movimento ambientalista brasileiro: uma contribuição à crítica do movimento. Blumenau: Edifurb/Editora da UFSC, 2000, 116 p.

BAUDRILLARD, Jean. A sociedade de consumo. Rio de Janeiro: Elfos, 1995.

BOFF, Leonardo. Ethos mundial: um consenso minimo. Rio de Janeiro: Sextante, 2003, 131p.

BRANDÃO, Carlos Rodrigues. A canção das sete cores: educando para a paz. São Paulo: Contexto, 2005, 220p.

CANCLINI, Néstor García. Consumidores e cidadãos: conflitos multiculturais da globalização. Rio de Janeiro: Ed.UFRJ, 1996, 290p.

CAIRNCROSS, Frances. Meio Ambiente: custos e beneficios. São Paulo: Nobel, 1992, 267p.

ECKENSBERGER, Lutz H. Juízos morais no contexto de orientações de valores econômicos e ecológicos: o caso de uma usina de força abastecida a carvão. In: TASSARA, Eda Terezinha de Oliveira. (Org.) Panoramas interdisciplinares para uma psicologia ambiental do urbano. São Paulo: EDUC: FAPESP, 2001, p. 141-186.

GEERTZ, C. A interpretação das culturas. Rio de Janeiro: Zahar, 1989, 323p. 
GUATTARI, Félix. As três ecologias. Campinas: Papirus Editora, 1990, 56p.

HALL, Edward T. La dimension cachée, Paris: Le Seuil, 1971, 256p.

IANNI, Otávio. O cidadão do mundo. In: LOMBARDI, José Claudinei, SAVIANI, Dermeval, SANFELICE, José Luis (Orgs.). Capitalismo, trabalho e educaşão. Campinas, SP: Autores Associados, Histedbr, 2002. p. 27-34

KEHL, Maria Rita. O fetichismo. In: SADER, Emir. Sete pecados do capital. Rio de Janeiro: Record, 1999, p.79-106.

KOSTROWICHI, Andrej S. Problemas Sociais da Política do Meio Ambiente. Rev. Geogr., São Paulo, 7, p.65-74, 1988.

LABORIT, Henri. Société Informationnelle: idées pour l'autogestion. Paris: Les Éditions du Cerf, 1973.

LEFEBVRE, Henri. Critique de la vie quotidienne. Paris: Éditions l'Arche , V. I: "Introduction", 1958, p. 240.

LEVY, Michel. Traité d'bygiène publuque et privée. $5^{\text {a }}$ ed., t.II, 1869.

MADEIRA, Margot Campos. Representações Sociais e Educação: importância teórico-metodológica de uma relação. In: MOREIRA, Antonia. S. Paredes. (Org.) Representações Sociais: teoria e prática. João Pessoa: Ed. Universitária UFPB, 2001, p. 123-144.

\& ALLOUFA, Jomária Mata de Lima. Representações sociais e Educação: que relação é esta ? In: II Colóquio Franco-Brasileiro Educação e Linguagem, Natal (RN), 1996. Anais... UFRN - Université de Caen. EDUFRN (RN), p. 11-15, 1997.

MARCUSE, Herbert. Five Lectures: Psychoanalysis, Politics and Utopia. Boston: Beacon Press, 1970, 109p.

MESZAROS, Istvan. The necessity of social control. London: The Merlin Press, 1971

MORIN, Edgar. A Cabeça Bem-Feita: reformar a reforma, reformar o pensamento. São Paulo: Ed. Bertrand Brasil, 2000(a), 128p. Os Sete Saberes Necessários à Educação no Futuro. São Paulo: Cortez 
Ed., 2000 (b), 118p

A religação dos saberes: o desafio do século XXI. Rio de Janeiro: Bertrand Brasil, 2001, 588p

1996, 163p

\& KERN, Anne Brigitte. Terra-Pátria. Lisboa: Instituto Piaget,

ORTEGA Y GASSET, José. Meditaciones del Quijote. Madrid: Alianza, 2001, $167 \mathrm{p}$.

PORTILHO, Fátima. Consumo "verde", democracia ecológica e cidadania: possibilidades de diálogo? Disponível na Internet no sítio: http://www.rubedo.psc.br/Artigos/consumo.htm

SANTANA, Paola Verri. Da socialização à mundialização da natureza. In: CARLOS, Ana Fani Alessandri. (Org.) Ensaios de Geografia contemporânea. Milton Santos: obra revisitada. São Paulo: Hucitec, 1996, 254p.

SANTOS, Boaventura de Sousa. A crítica da razão indolente: contra o desperdício da experiência. Para um novo senso comum. A ciência, o direito e a política na transição paradigmática. São Paulo: Cortez, 3. ed., V. 1, 2001, 415p.

SANTOS, Milton. Metamorfoses do espaço habitado. São Paulo: Hucitec, 1988, $124 p$

O Espaço do Cidadão. São Paulo: Nobel, 1993. 142p.

Técnica, Espaço, Tempo - Globalização e Meio Técnico-Cientifico-

Informacional. São Paulo: Hucitec, 1994, 190p

- A natureza do espaço: técnica e tempo. Razão e emoção. São Paulo: HUCITEC, 1996, 388p.

Território e Sociedade - entrevista com Milton Santos. São Paulo: Ed.

Fundação Perseu Abramo, 2000. 128p.

- Por Uma Outra Globalização - Do Pensamento Único à Consciência

Universal. São Paulo: Ed. Record, 2001. 138p.

Deficientes Cívicos. Folha on-line, São Paulo, 23 de maio 2002.

Disponível em: <http://www.uol.com.br/fol/brasil500/dc39.htm>. Acesso em: 30 de maio 2002. 
SAWAIA, Bader Burihan. Participação social e subjetividade. In: SORRENTINO, Marcos. (coord.) Ambientalismo e participação na contemporaneidade. São Paulo, EDUC: FAPESP, 2001, p. 115-134

SPOSATI, Aldaíza. Movimentos utópicos da contemporaneidade. In: SORRENTINO, Marcos. (coord.) Ambientalismo e participação na contemporaneidade. São Paulo: EDUC: FAPESP, 2001, p. 57-85. 